OPEN ACCESS

Edited by:

Hector Mora Montes,

Universidad de Guanajuato, Mexico

Reviewed by:

Monika Staniszewska,

National Institute of Public Health

Poland

José Ascención Martínez-Álvarez, Universidad de Guanajuato, Mexico

${ }^{*}$ Correspondence:

Zhibin Shen

shenz123@163.com

Chunping Tang

tchp66@163.com

${ }^{+}$These authors have contributed equally to this work

Specialty section:

This article was submitted to Fungi and Their Interactions,

a section of the journal

Frontiers in Microbiology

Received: 17 July 2018 Accepted: 05 September 2018 Published: 02 November 2018

Citation:

Ye L, Lin P, Du W, Wang Y, Tang C and Shen $Z$ (2018) Preparation,

Antidermatophyte Activity, and Mechanism

of Methylphloroglucinol Derivatives.

Front. Microbiol. 9:2262.

doi: 10.3389/fmicb.2018.02262

\section{Preparation, Antidermatophyte Activity, and Mechanism of Methylphloroglucinol Derivatives}

\author{
Lianbao Ye ${ }^{1 \dagger}$, Pengfei $\mathrm{Lin}^{2 \dagger}$, Wenjun Du${ }^{1}$, Yuanyuan Wang ${ }^{1}$, Chunping Tang ${ }^{2 \star}$ and \\ Zhibin Shen ${ }^{2 *}$ \\ ${ }^{1}$ School of Pharmacy, Key Laboratory of New Drug Discovery and Evaluation of Ordinary Universities of Guangdong \\ Province, Guangdong Pharmaceutical University, Guangzhou, China, ${ }^{2}$ School of Traditional Chinese Medicine, Guangzhou \\ Key Laboratory of Construction and Application of New Drug Screening Model Systems, Guangdong Pharmaceutical \\ University, Guangzhou, China
}

In this study a variety of phloroglucinols were isolated from the plant, and the activity experiment showed that the phloroglucinols had strong antifungal activity, especially methylphloroglucinol derivatives such as aspidin PB, dryofragin, aspidinol, aspidin BB, aspidin $A B$, and albicanol, in which the hydroxyl group of methylphloroglucinol is the active group of compounds, and C-2 or C-6 is the active site. The introduction of different groups in this position could change the properties and bioactivity of the compounds. In this study, different functional groups were introduced to the structure of methylphloroglucinol to obtain methylphloroglucinol derivatives that were synthesized, and antidermatophyte activities on Trichophyton rubrum, Trichophyton mentagrophytes, Microsporum canis, and Gypsum microspore bacteria were evaluated. Molecular docking verified its ability to combine the protein binding site. The antidermatophyte mechanism of compounds on cytochrome P450 sterol 14a-demethylase, squalene epoxidase, and $\beta$-1,3-glucan synthase was investigated by the enzyme-linked immunosorbent assay. The results showed that compounds had an inhibitory effect on four kinds of common dermatophytes in varying degrees, in which compound $\mathbf{g}$ had the strongest activities, the binding mode of methylphloroglucinol and its derivatives were similar to those of three enzymes, and compounds $\mathbf{e}$ and $\mathbf{g}$ had significant effects on the activity of the three enzymes, and compound $\mathbf{g}$ had a slightly stronger effect than the blank group. Compounds $\mathbf{e}$ and $\mathbf{g}$ also had a significant effect on the ergosterol synthesis of $M$. canis. This study could supply some antidermatophyte leading structure and possible mechanism for studying and developing new antifungal agents.

Keywords: methylphloroglucinol derivatives, preparation, antidermatophyte activity, molecular simulation, antidermatophyte mechanism

\section{INTRODUCTION}

Fungi on skin are widely distributed in nature and frequently present as pathogens in the animal and plant kingdoms (Ruhnke et al., 2011). In recent decades, despite progress in antidermatophyte therapy, fungal infections on skin have remained a major global health concern, due to the development of antifungal drug resistance (Tsui et al., 2016; Shrestha et al., 2017). However, the emergence of resistance to antifungal drugs by diverse pathogenic fungal strains has resulted in an increase in demand for new antifungal agents (Araj et al., 2015). The widely used clinical 
antifungals are azoles, polyenes, allylamines, and echinocandins. These antifungal scaffolds are known to function by different mechanisms (Kathiravan et al., 2012; Xie et al., 2015). Currently, main targets of the antifungal agents are cytochrome P450 sterol 14a-demethylase (CYP51), squalene epoxidase (SE), and $\beta$-1,3-glucan synthase, in which azole and triazole drugs are CYP51 inhibitors widely used as antifungal, antibiotics, and antimycobacterial drugs, spinosins are $\beta$-1,3-glucan synthase inhibitors, and allylamine agents act on SE (Huang et al., 2009; Gil-Alonso et al., 2016; Mazu et al., 2016; Yang and Xu, 2016).

Dryopteris fragrans was mainly used as a folk medicine at present. It has been found that the main active compounds of $D$. fragrans have a significant effect on a variety of skin diseases caused by fungi (Wan et al., 2014; Zhao et al., 2014; Wang et al., 2015; Du et al., 2016; Huang et al., 2016). Our group isolated a variety of phloroglucinols from the plant, and the activity experiment showed that the phloroglucinols had strong antifungal activity, especially methylphloroglucinol derivatives such as aspidin $\mathrm{PB}$, dryofragin, aspidinol, aspidin $\mathrm{BB}$, aspidin $\mathrm{AB}$, and albicanol, in which the hydroxyl group of methylphloroglucinol is the active group of compounds, and C-2 or C-6 is the active site (Sun et al., 2013; Li et al., 2014; Gao et al., 2016). The introduction of different groups in this position may change the properties and bioactivity of the compounds (Yang, 2017; Lin et al., 2018). In this study, different functional groups were introduced to the structure of methylphloroglucinol to obtain new methyl phloroglucinol derivatives that were synthesized, and antidermatophyte activities on Trichophyton (T.) rubrum, Trichophyton (T.) mentagrophytes, Microsporum (M.) canis, and Gypsum (G.) microspore (M.) bacteria were evaluated. Molecular docking verified its ability to combine the protein binding site. The antidermatophyte mechanism of compounds on CYP51, SE, and $\beta$-1,3-glucan synthase was investigated by the enzyme-linked immunosorbent assay (ELISA), and the effect of compounds $\mathbf{e}$ and $\mathbf{g}$ on the ergosterol synthesis of $M$. canis was investigated by ultra performance liquid chromatography (UPLC). This study can supply some antidermatophyte leading structure and possible mechanism for studying and developing new antifungal agents, and it can give foundation of the development of new antifungal drugs of independent intellectual property rights.

\section{RESULTS AND DISCUSSION}

\section{Chemistry}

In order to study the antidermatophyte activities of methylphloroglucinol derivatives, we synthesized $\mathbf{c}$ analogs to explore the correlation of antidermatophyte activity. We used a divergent strategy to introduce structurally different linkers on C- 2 or C-6 of the methyl phloroglucinol moieties. Our group isolated a variety of phloroglucinols from the plant, and the activity experiment showed that the phloroglucinols had strong antifungal activity, such as aspidin $\mathrm{PB}$, dryofragin, aspidinol, aspidin $\mathrm{BB}$, aspidin $\mathrm{AB}$, and albicanol, and the C-6 position of these compounds has the $\mathrm{C}_{1}-\mathrm{C}_{4}$ acyl group. In this study, we introduced butyryl and antifungal pharmacophore allylamine into the methylphloroglucinol and/or kept the $\mathrm{C}_{1}-\mathrm{C}_{4}$ acyl group in the C- 6 position using pseudoaspidinol as a lead compound to obtain novel phloroglucinol derivatives $\mathbf{d}-\mathbf{g}$. The synthetic route of the compounds is shown in Figure $\mathbf{1}$. The methylphloroglucinol was successfully synthesized using 1,3,5-hydroxybenzene (a) as raw material by the Vilsmeier-Haack reaction and reduction reaction. As a result, four derivatives, 2-butyryl-4-methylbenzene-1,3,5-triol (d), 2,6-dibutyryl-4-methylbenzene-1,3,5-triol (e), (E)-2(4-aminobut-2-enyl)-4-methylbenzene-1,3,5-triol (f), and (E)-6-(4-aminobut-2-enyl)-2-butyryl-4-methylbenzene-1,3,5triol (g) were obtained with the yield of 28.6, 57.2, 35.7, and $81.2 \%$, respectively.

\section{2-Methylbenzene-1,3,5-triol (c)}

Yield: $78 \%$, white solid, Mp: $231-234^{\circ} \mathrm{C},{ }^{1} \mathrm{H}$ nuclear magnetic resonance (NMR) $\left(500 \mathrm{MHz}, \mathrm{CDCl}_{3}\right): \delta(\mathrm{ppm}) 10.29(\mathrm{~s}, 1 \mathrm{H}, 4-$ $\mathrm{OH}), 9.68$ (s, 2H, 2-OH, 6-OH), 5.76 (s, 2H, H-3, 5), 1.80 (s, 3H, $\mathrm{H}-7) .{ }^{13} \mathrm{C} \mathrm{NMR}\left(125 \mathrm{MHz}, \mathrm{CDCl}_{3}\right.$ ): $\delta$ (ppm) 160.0, 160.0, 157.9, 102.9, 96.4, 96.4, 27.1. EI-MS: $141.14[\mathrm{M}+\mathrm{H}]^{+}$. Anal. calcd for $\mathrm{C}_{7} \mathrm{H}_{8} \mathrm{O}_{3}$ (140.05): C, 59.99; H, 5.75; O, 34.25; Found: C, 59.94; H, $5.72 ; \mathrm{O}, 34.34$.

\section{2-Butyryl-4-methylbenzene-1,3,5-triol (d)}

Yield: $28.6 \%$, white solid, Mp: $161-164^{\circ} \mathrm{C},{ }^{1} \mathrm{H}$ NMR $(500 \mathrm{MHz}$, $\left.\mathrm{CDCl}_{3}\right): \delta(\mathrm{ppm}) 10.18$ (s, $\left.1 \mathrm{H}, \mathrm{H}-2 \mathrm{OH}\right), 9.89$ (s, $\left.1 \mathrm{H}, \mathrm{H}-4 \mathrm{OH}\right)$, 9.21 (s, 1H, H-6OH), 5.63 (s, 1H, H-5), 2.97 (s, 2H, J = 5.5, H-9), 2.03-2.09 (m, 2H, H-10), 1.86 (s, 3H, H-7), 1.17-1.20 (m, 3H, H11). $\left.{ }^{13} \mathrm{C} \mathrm{NMR} \mathrm{(125} \mathrm{MHz,} \mathrm{CDCl}_{3}\right): \delta$ (ppm) 187.6, 161.0, 161.7, 156.9, 105.1, 103.7, 90.6, 46.0, 27.3, 18.2, 13.7. EI-MS: 209.71 $[\mathrm{M}+\mathrm{H}]^{+}$. Anal. calcd for $\mathrm{C}_{11} \mathrm{H}_{14} \mathrm{O}_{4}$ (210.09): C, 62.85; H, 6.71; O, 30.44; Found: C, 62.89; H, 6.70; O, 30.41 .

\section{2,6-Dibutyryl-4-methylbenzene-1,3,5-triol (e)}

Yield: $47.2 \%$, yellow solid, Mp: $260-263^{\circ} \mathrm{C},{ }^{1} \mathrm{H}$ NMR $(500 \mathrm{MHz}$, $\left.\mathrm{CDCl}_{3}\right): \delta(\mathrm{ppm}) 10.18$ (s, 1H, 2-OH), 9.89 (s, 1H, 4-OH), 9.21 (s, 1H, 6-OH), 2.97 (s, 4H, J = 5.5, H-9, H-13), 2.03-2.09 (m, 4H, H-10, H-14), 1.86 (s, 3H, H-7), 1.17-1.20 (m, 6H, H-11, H15). ${ }^{13} \mathrm{C} \mathrm{NMR}\left(125 \mathrm{MHz}, \mathrm{CDCl}_{3}\right): \delta$ (ppm) 187.6, 187.6, 161.0, $161.7,156.9,105.1,103.7,90.6,46.0,46.0,27.3,18.2,18.2,13.7$, 13.7. EI-MS: $279.88[\mathrm{M}+\mathrm{H}]^{+}$. Anal. calcd for $\mathrm{C}_{15} \mathrm{H}_{20} \mathrm{O}_{5}$ (280.13): C, 64.27; H, 7.19; O, 28.54; Found: C, 64.30; H, 7.13; O, 28.57.

\section{(E)-2-(4-Aminobut-2-enyl)-4-methylbenzene-1,3,5- triol $(f)$}

Yield: $81.2 \%$, brown solid, Mp: $282-285^{\circ} \mathrm{C},{ }^{1} \mathrm{H}$ NMR $(500 \mathrm{MHz}$, $\left.\mathrm{CDCl}_{3}\right): \delta(\mathrm{ppm}) 10.08$ (s, 1H, 2-OH), 9.81 (s, 1H, 4-OH), 9.11(s, $1 \mathrm{H}, 6-\mathrm{OH}), 5.92-5.98$ (m, 2H, H-9, H-10), 5.53 (s, 1H, H-5), 1.80 (s, 3H, H-7), 1.69-1.79 (m, 4H, H-8, H-11). ${ }^{13} \mathrm{C}$ NMR (125 MHz, $\left.\mathrm{CDCl}_{3}\right): \delta(\mathrm{ppm}) 160.1,159.7,156.1,128.6,114.5,104.9,104.1$, 90.5, 43.0, 26.5, 19.2. EI-MS: $210.32[\mathrm{M}+\mathrm{H}]^{+}$. Anal. calcd for $\mathrm{C}_{11} \mathrm{H}_{15} \mathrm{NO}_{3}$ (209.11): C, 63.14; H, 7.23; N, 6.69; O, 22.94; Found: C, 63.10; H, 7.24; N, 6.75; O, 22.91. 


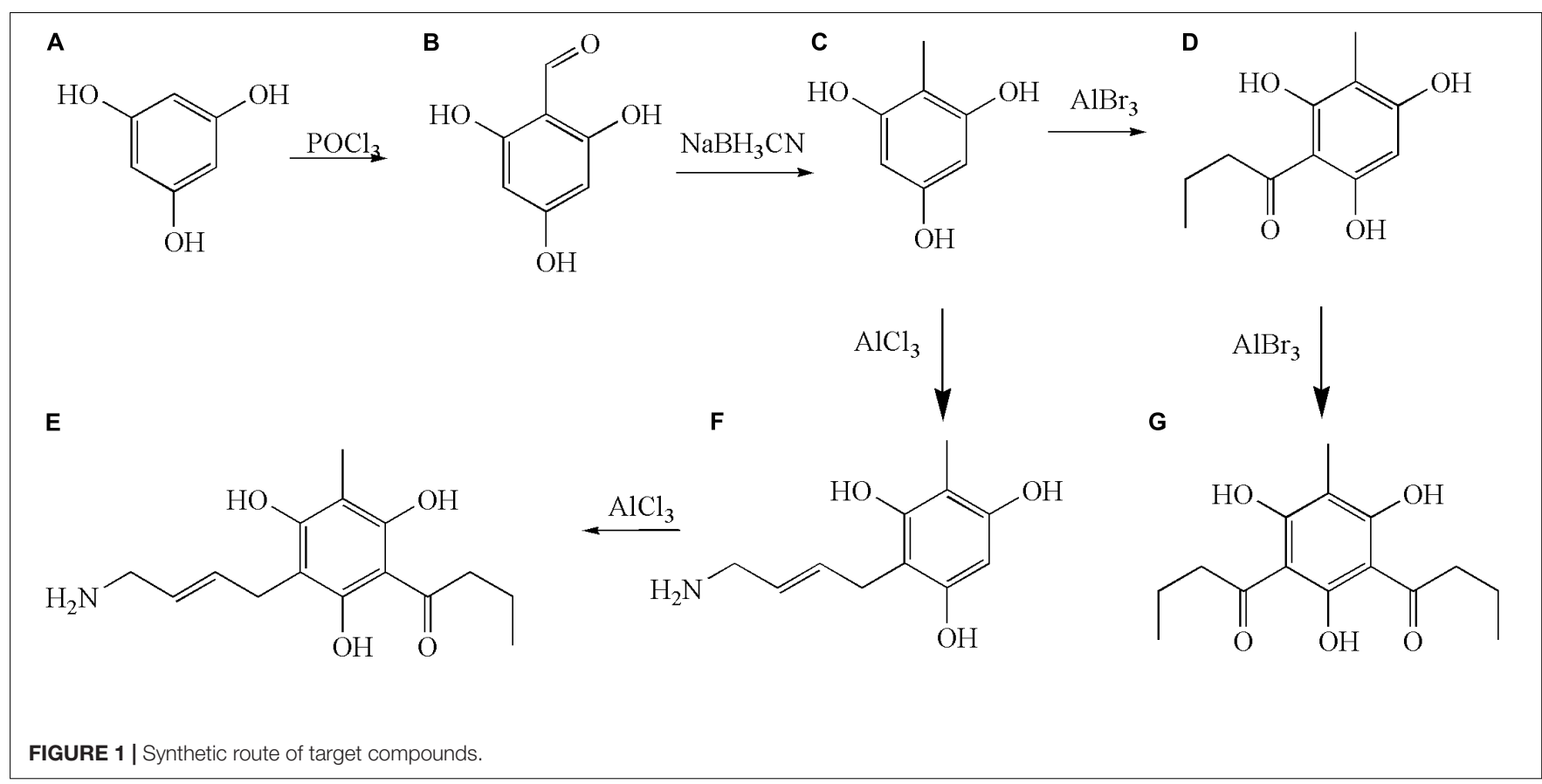

\section{(E)-6-(4-Aminobut-2-enyl)-2-butyryl-4- methylbenzene-1,3,5-triol (g)}

Yield: $48.7 \%$, brown solid, Mp: $385-388^{\circ} \mathrm{C},{ }^{1} \mathrm{H}$ NMR $(500 \mathrm{MHz}$, $\left.\mathrm{CDCl}_{3}\right): \delta(\mathrm{ppm}) 9.98(\mathrm{~s}, 1 \mathrm{H}, 2-\mathrm{OH}), 9.71(\mathrm{~s}, 1 \mathrm{H}, 4-\mathrm{OH}), 9.17(\mathrm{~s}$, $1 \mathrm{H}, 6-\mathrm{OH}), 5.81-5.91(\mathrm{~m}, 2 \mathrm{H}, \mathrm{H}-9, \mathrm{H}-10), 2.91$ (s, $2 \mathrm{H}, J=5.5$, H-13), 2.13-2.19 (m, 2H, H-14), 1.80 (s, 3H, H-7), 1.69-1.79 (m, $4 \mathrm{H}, \mathrm{H}-8, \mathrm{H}-11), 1.07-1.19$ (m, 3H, H-15). ${ }^{13} \mathrm{C}$ NMR $(125 \mathrm{MHz}$, $\left.\mathrm{CDCl}_{3}\right): \delta(\mathrm{ppm}) 187.6,160.1,159.7,156.1,128.6,114.5,105.1$, 103.7, 90.6, 46.0, 43.0, 27.3, 26.5, 18.2, 13.7. EI-MS: 280.89 $[\mathrm{M}+\mathrm{H}]^{+}$. Anal. calcd for $\mathrm{C}_{15} \mathrm{H}_{21} \mathrm{NO}_{4}$ (279.15): C, 64.50; $\mathrm{H}$, 7.58; N, 5.01; O, 22.91; Found: C, 64.53; H, 7.56; N, 4.98; O, 22.93 .

\section{In vitro Antidermatophyte Assay}

In order to investigate their potential as antidermatophyte agents, according to the CLSI M38-A2 Reference Method for Antifungal Susceptibility Testing, the microdilution method was used to investigate the antidermatophyte activities of methylphloroglucinol derivatives $\mathbf{b}-\mathbf{g}$ along with those for two known antifungal drugs [terbinafine hydrochloride (TBF), miconazole nitrate (MCZ)] on four dermatophytes (T. rubrum, T. mentagrophytes, M. canis, G. M. bacteria). The minimal inhibitory concentrations (MICs) and minimal fungicidal concentrations (MFCs) of compounds against the four dermatophytes are shown in Table 1. The MIC was defined as the lowest concentration that completely inhibited visible fungal growth in the wells after 7 days of incubation, and the MFC was indicated by the well that showed no growth after culturing on the Sabouraud dextrose agar medium. Since triazole drug MCZ and allylamine agent TBF are widely used as antifungal, respectively, act on CYP51 inhibitors and SE, we chose MCZ and TBF as positive control. Cell suspensions (200 $\mu \mathrm{L})$ containing $0.156-160 \mu \mathrm{g} / \mu \mathrm{L}$ of compounds were added to the wells of a 96-well microtiter plate and incubated for $48 \mathrm{~h}$ at $35^{\circ} \mathrm{C}$. The six compounds showed an inhibitory effect on the four dermatophytes in varying degrees. Because compounds had lower antidermatophyte activities than the positive control group, antidermatophyte activities were comparative between compound groups. The strong and weak order of antidermatophyte activities were as follows: g-e-b-d-c-f, in which compound $\mathbf{g}$ has the strongest antidermatophyte activities, especially on $M$. canis with the MIC value of $10 \mu \mathrm{g} / \mathrm{mL}$; the inhibitory effect of compounds $\mathbf{c}$ and $\mathbf{f}$ is not obvious. It was worth noting that these compounds had strong inhibition on T. mentagrophytes and M. canis. The MIC values of $\mathbf{e}$ and g on the four dermatophytes were very close, especially on T. mentagrophytes and M. canis. Compounds e and $\mathbf{g}$ had stronger inhibition on M. canis. So we chose M. canis to perform time-kill curve assay research.

\section{Time-Kill Curve Assays}

In order to understand the rate of the antidermatophyte activity, compounds e and $\mathbf{g}$ were selected for time-kill assays against the $M$. canis owing to stronger inhibition of compounds e and $\mathbf{g}$ on $M$. canis. The time-kill curve of compounds $\mathbf{e}$ and $\mathbf{g}$ was as shown in Figure 2. The colonies of different time points in TimeKill Curve were seen in Supplementary Material. Compounds e and $\mathbf{g}$ against $M$. canis were investigated by the colony counting method. The limit of quantitation indicated that there was no colony growth on plate medium. The results showed that the two derivatives could inhibit the growth of $M$. canis for a certain period of time, and when the drug concentration was less than MIC, the two derivatives could inhibit the growth of $M$. canis. The difference was that when the drug concentration was between MIC and 2MIC, compound $\mathbf{g}$ was stronger than compound e to kill M. canis. 
TABLE 1 | Minimal inhibitory concentrations (MICs) and MFCs of compounds against four dermatophytes.

\begin{tabular}{|c|c|c|c|c|c|c|c|c|}
\hline & \multicolumn{2}{|c|}{ Trichophyton rubrum $(\mu \mathrm{g} / \mathrm{mL})$} & \multicolumn{2}{|c|}{ Trichophyton mentagrophytes $(\mu \mathrm{g} / \mathrm{mL})$} & \multicolumn{2}{|c|}{ Gypsum microspore bacteria $(\mu \mathrm{g} / \mathrm{mL})$} & \multicolumn{2}{|c|}{ Microsporum canis $(\mu \mathrm{g} / \mathrm{mL})$} \\
\hline & MIC & MFC & MIC & MFC & MIC & MFC & MIC & MFC \\
\hline b & 125 & 250 & $>160$ & $>160$ & 62.5 & 125 & 30 & 30 \\
\hline c & $>160$ & $>160$ & $>160$ & $>160$ & $>160$ & $>160$ & $>160$ & $>160$ \\
\hline d & 125 & 250 & 62.5 & 62.5 & 250 & 250 & 125 & 125 \\
\hline e & 160 & 160 & 20 & 20 & 20 & 20 & 20 & 20 \\
\hline f & $>320$ & $>320$ & $>320$ & $>320$ & $>320$ & $>320$ & $>320$ & $>320$ \\
\hline g & 60 & 80 & 20 & 20 & 20 & 20 & 10 & 10 \\
\hline TBF & 0.16 & 0.32 & 0.05 & 0.25 & 0.25 & 0.5 & 0.25 & 0.5 \\
\hline MCZ & 0.25 & 0.25 & 0.25 & 0.5 & 0.5 & 1 & 0.5 & 1 \\
\hline
\end{tabular}

MCZ, miconazole nitrate; TBF, terbinafine hydrochloride.

TABLE 2 | Effects of different concentrations of drugs on ergosterol in Microsporum canis.

\begin{tabular}{|c|c|c|c|}
\hline \multicolumn{2}{|c|}{ Group } & \multirow{2}{*}{$\begin{array}{c}\text { Ergosterol content }(\mathbf{m g} / \mathbf{g}) \\
0.2754 \pm 0.085\end{array}$} & \multirow{2}{*}{$\begin{array}{c}\text { Decrease rate of ergosterol content (\%) } \\
-\end{array}$} \\
\hline & & & \\
\hline \multirow[t]{3}{*}{ Compound e } & 1/2MIC & $0.2035 \pm 0.015^{*}$ & 13.55 \\
\hline & $\mathrm{MIC}$ & $0.1738 \pm 0.018^{*}$ & 26.17 \\
\hline & $2 \mathrm{MIC}$ & $0.1223 \pm 0.032 *$ & 55.59 \\
\hline \multirow[t]{5}{*}{ Compound $\mathbf{g}$} & 1/2MIC & $0.1983 \pm 0.013^{*}$ & 15.76 \\
\hline & $\mathrm{MIC}$ & $0.1547 \pm 0.023^{*}$ & 34.28 \\
\hline & $2 \mathrm{MIC}$ & $0.1189 \pm 0.016^{*}$ & 56.83 \\
\hline & TBF & $0.1286 \pm 0.019 *$ & 45.37 \\
\hline & MCZ & $0.1198 \pm 0.030^{*}$ & 49.11 \\
\hline
\end{tabular}

MIC e-value, $20 \mu \mathrm{g} / \mathrm{mL}$; MIC g-value, $10 \mu \mathrm{g} / \mathrm{mL}$; MCZ, miconazole nitrate; TBF, terbinafine hydrochloride. * Comparison with blank group, $P$ < 0.05 .

\section{Effect of Compounds e and $g$ on Ergosterol Synthesis of $M$. canis}

In a previous study, we found that active composition of $D$. fragrans (L.) Schott influenced the cell wall to inhibited growth of T. rubrum and T. mentagrophytes by inhibiting $\beta-1,3-$ glucan synthase, which is the key kinase of ergosterol synthesis. So we determined ergosterol content of M. canis by UPLC to investigate the effect of compounds $\mathbf{e}$ and $\mathbf{g}$ on the ergosterol synthesis of $M$. canis before and after administration. The results were as shown in Figure 3. Compared with the blank group, the ergosterol content in M. canis decreased significantly after administration. When the concentration of compound $\mathbf{g}$ was 1/2MIC, MIC, and 2MIC, the decreased rate of ergosterol content was $15.76,34.28$, and $56.83 \%$, respectively, which was higher than those of compound $\mathbf{e}$ with the decreased rate of $13.55,26.17$, and $55.59 \%$. The decreased rate of ergosterol content in MIC groups of TBF and MCZ was 45.37 and $49.11 \%$, respectively, as seen in Table 2.

\section{Effect of Compounds e and $g$ on CYP51, SE, and $\beta-1,3-$ Glucan Synthase}

The effect of compounds $\mathbf{e}$ and $\mathbf{g}$ on the ergosterol synthesis of $M$. canis showed that compounds $\mathbf{e}$ and $\mathbf{g}$ could inhibit the synthesis of ergosterol (Table 3). CYP51 and SE are key enzymes of ergosterol synthesis. So we deduced that methylphloroglucinol derivatives should inhibit ergosterol synthesis by inhibiting
CYP51 and SE to affect the formation of fungal cell membrane. Currently, the main targets of the antifungal agents are CYP51, $\mathrm{SE}$, and $\beta$-1,3-glucan synthase. In the present study, the effects of compounds $\mathbf{e}$ and $\mathbf{g}$ on CYP51, SE, and $\beta$-1,3-glucan synthase were investigated by ELISA using TBF, MCZ, and caspofungin acetate as positive control. The results are shown in Figure 4. The results showed that compounds $\mathbf{e}$ and $\mathbf{g}$ had significant inhibitions $(P<0.01)$ on three enzymes when the concentration of the compounds was $2 \mathrm{MIC}$, and compound g had a slightly stronger effect than the blank group and stronger inhibition than compound e. With the increase in the concentration of the compounds, their activities against the three target enzymes decreased in a dose-dependent manner. According to the results of compounds $\mathbf{e}$ and $\mathbf{g}$ on the ergosterol synthesis of $M$. canis, we could deduce through the antifungal mechanism that compounds $\mathbf{e}$ and $\mathbf{g}$ made the ergosterol content in M. canis decrease by inhibiting the activities of CYP51 and $\mathrm{SE}$, which resulted in synthesis failure of the cell film, blocking the synthesis of the fungal cell wall by inhibiting $\beta-1,3$-glucan synthase.

\section{Docking Studies}

Currently, the main targets of the antifungal agents are CYP51, $\mathrm{SE}$, and $\beta$-1,3-glucan synthase, in which azole and triazole drugs are CYP51 inhibitors widely used as antifungal and antimycobacterial activity, spinosins are $\beta$-1,3-glucan synthase inhibitors, and allylamine agents act on SE (Huang et al., 


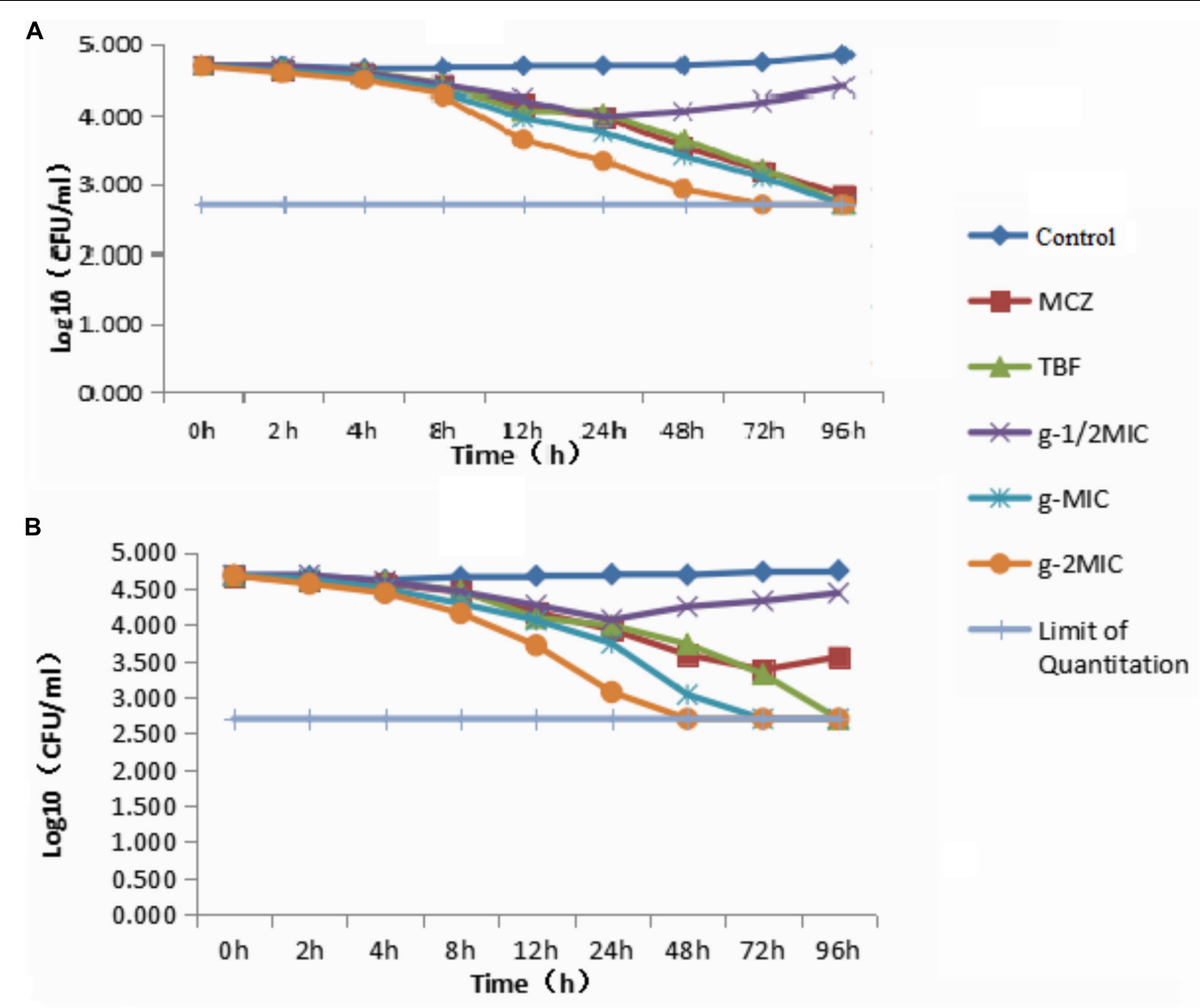

FIGURE 2 | Time-kill curve: (A) Time-kill curve of compound e against Microsporum canis; (B) time-kill curve of compound $\mathbf{g}$ against $M$. canis. (The limit of quantitation indicated that there was no colony growth on plate medium.)

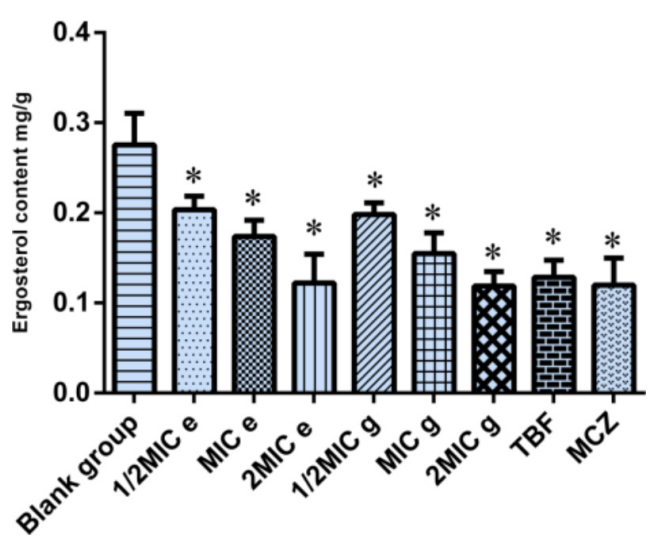

FIGURE 3 | Effect of compounds e and $\mathbf{g}$ on the ergosterol synthesis of Microsporum canis (blank group, ergosterol; MIC e-value, $20 \mu \mathrm{g} / \mathrm{mL}$; MIC $\boldsymbol{g}$-value, $10 \mu \mathrm{g} / \mathrm{mL}$; MCZ, miconazole nitrate; TBF, terbinafine hydrochloride; *comparison with blank group, $P<0.05)$.

2009; Gil-Alonso et al., 2016; Mazu et al., 2016; Yang and $\mathrm{Xu}, 2016)$. In this study, we investigated the interaction of compounds with protein sites of kinases. The X-ray crystallographic structures of CYP51 (PDB ID: 3LD6), SE (PDB ID:1SQC), and $\beta$-1,3-glucan synthase (PDB ID: 1LQ2) were taken from $\mathrm{PDB}^{1}$. Enzyme crystal complexes are shown in Figure 5.

The binding energies of complexes between each compound and the active sites of the receptor are shown in Table 4 . Compounds e and $\mathbf{g}$ had higher binding energies in accordance with the results of antidermatophyte activities, which further confirmed inhibition of compounds $\mathbf{e}$ and $\mathbf{g}$ on CYP51, SE, and $\beta$-1,3-glucan synthase. It is noteworthy that compound b had stronger inhibition on $M$. canis but lower binding energies. Docking conformations of compounds $\mathbf{b}$, e, and g with the active sites of protein 3LD6, 1SQC, and 1LQ2 are shown in Figures 6-8, respectively. Results of docking showed that the binding modes of compounds to protein sites of CYP51, SE, and $\beta$-1,3-glucan enzyme were similar, which interacted through hydrogen bonding formed by $\mathrm{H}$ or $\mathrm{O}$ in compound molecule and $\mathrm{O}$ or $\mathrm{H}$ in amino acid, hydrophobic interaction and $\mathrm{Pi}-\mathrm{Pi}$ interaction between the benzene ring and the TRP amino acid group. All compounds could combine with TRP34, MET316, GLU491,

\footnotetext{
${ }^{1}$ www.rcsb.org/pdb
} 
TABLE 3 | Effect of compounds e and $\mathbf{g}$ on squalene epoxidase, CYP51, and $\beta$-1,3-glucan synthase.

\begin{tabular}{|c|c|c|c|c|c|}
\hline \multicolumn{2}{|c|}{ Group } & \multirow{2}{*}{$\begin{array}{l}\text { Drug concentration } \\
\qquad \begin{array}{c}(\mu \mathrm{g} / \mathrm{mL}) \\
-\end{array}\end{array}$} & \multirow{2}{*}{$\begin{array}{c}\text { Squalene epoxidase } \\
\text { (U/L) }(\mathbf{X} \pm \text { SD) }\end{array}$} & \multirow{2}{*}{$\begin{array}{c}\begin{array}{c}\text { CYP51(U/L) } \\
(X \pm S D)\end{array} \\
437.39 \pm 6.58\end{array}$} & \multirow{2}{*}{$\begin{array}{c}\boldsymbol{\beta}-\mathbf{1 , 3 - G l u c a n} \text { synthase } \\
\text { (U/L) }(\mathbf{X} \pm \mathrm{SD})\end{array}$} \\
\hline & & & & & \\
\hline Compound e & 1/2MIC & 10 & $387.65 \pm 4.68^{*}$ & $359.97 \pm 8.16^{*}$ & $196.10 \pm 3.28^{* *}$ \\
\hline & MIC & 20 & $359.37 \pm 2.01^{*}$ & $308.46 \pm 7.75^{*}$ & $156.62 \pm 1.77^{* *}$ \\
\hline & $2 \mathrm{MIC}$ & 40 & $307.25 \pm 8.75^{* *}$ & $300.25 \pm 3.87^{* *}$ & $157.87 \pm 5.64^{* *}$ \\
\hline \multirow[t]{3}{*}{ Compound g } & 1/2MIC & 5 & $382.77 \pm 7.37^{*}$ & $395.04 \pm 7.39^{*}$ & $185.50 \pm 9.09^{* *}$ \\
\hline & MIC & 10 & $366.62 \pm 0.53^{*}$ & $368.81 \pm 7.94^{*}$ & $167.86 \pm 5.78^{* *}$ \\
\hline & $2 \mathrm{MIC}$ & 20 & $270.1 \pm 3.89^{* *}$ & $304.99 \pm 8.51^{* *}$ & $150.85 \pm 3.64^{* *}$ \\
\hline TBF & & 0.25 & $151.06 \pm 4.74^{* *}$ & $383.98 \pm 8.9^{*}$ & 1 \\
\hline MCZ & & 0.5 & $276.89 \pm 7.47^{* *}$ & $292.34 \pm 3.31^{* *}$ & 1 \\
\hline Caspofungin a & & 0.25 & 1 & 1 & $151.95 \pm 5.72^{* *}$ \\
\hline
\end{tabular}

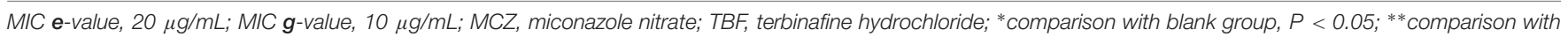
a blank group, $P<0.01$.

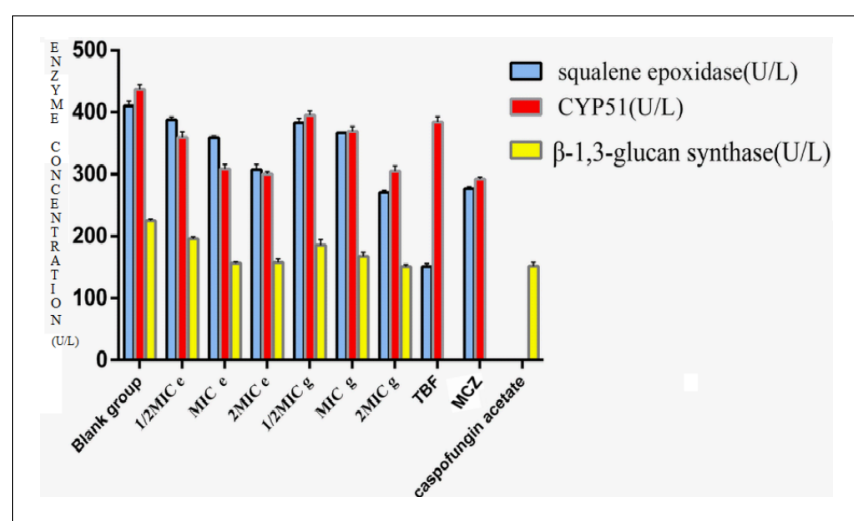

FIGURE 4 | Effect of compounds e and $\mathbf{g}$ on CYP51, squalene epoxidase, and $\beta$-1,3-glucan synthase. (MIC e-value, $20 \mu \mathrm{g} / \mathrm{mL}$; MIC $\boldsymbol{g}$-value, $10 \mu \mathrm{g} / \mathrm{mL}$; MCZ, miconazole nitrate; TBF, terbinafine hydrochloride.)
MET250, LYS206, TYR253, TRP286, GLY57, and PHE144. The differences were that compound $\mathbf{b}$ could combine with SER55, LEU54, GLY56, and MET250, compound e could combine with TRP266, HIS207, HOH848, and HOH869, and compounds g could combine with SER59, ASP285, MET316, LEU38, and GLU36, which could cause different activities of compounds. The binding effect of compounds $\mathbf{e}$ and $\mathbf{g}$ was stronger than that of compound b, which could be related to the butyryl and allylamino groups.

In order to explore the interaction of compounds with proteins, we carried out molecular dynamics, and the results are shown in Figure 9. The results of molecular dynamics showed that the root-mean-square deviation (RMSD) values of the three compounds remained 1.0-1.5 for the three enzyme kinetic simulations within $30 \mathrm{~ns}$, which indicated the rationality and stability of the molecular docking between the three compounds and 3LD6, 1SQC, and 1LQ2. The bind energies of compounds to the three enzymes are shown in Table 5. The binding energies of compounds $\mathbf{e}$ and $\mathbf{g}$ were higher than that of compound $\mathbf{b}$, which were consistent with the results of antidermatophyte activities.

\section{EXPERIMENTAL DETAILS}

\section{General Methods of Synthesis}

The solvents and reagents were purchased from commercial vendors and were dried and purified by conventional methods before use. NMR spectra were recorded on a Bruker AC300P spectrometer with tetramethylsilane (TMS) as the internal standard and $\mathrm{CDCl}_{3}$ as solvent. ESI mass spectra were performed on an API-3000 LC-MS spectrometer. TLC analysis was carried out on silica gel $60 \mathrm{~F}_{254}$ silica plates (Merck, KGaA, Germany).

\section{Synthesis of $b$}

Phosphorus oxychloride $(875 \mu \mathrm{L})$ was added to a solution of 1,3,5-hydroxybenzene (a) (500 $\mathrm{mg}, 3.97 \mathrm{mmol})$ and dimethylformamide $(725 \mu \mathrm{L})$ in ethyl acetate $(15 \mathrm{~mL})$, stirred for $2 \mathrm{~h}$ at room temperature, and filtered by vacuum. Solvent was evaporated to obtain the crude product, which was used for the next step.

\section{Synthesis of c}

To the solution of 1-formyl-2,4,6-trihydroxy benzene (b) (1.54 g, $10 \mathrm{mmol})$ in tetrahydrofuran $(20 \mathrm{~mL})$, we added methyl orange (1-2 drops) followed by the addition of sodium cyanoborohydride $(1.25 \mathrm{~g}, 20 \mathrm{mmol})$. The $\mathrm{pH}$ of the reaction mixture was maintained at 4.0. The reaction mixture was stirred for $12 \mathrm{~h}$ at room temperature and then extracted with ethyl acetate. The organic layer was washed with brine solution and finally dried over $\mathrm{Na}_{2} \mathrm{SO}_{4}$. Solvent was evaporated to obtain the crude product, which was purified by column chromatography with hexane/EtOAc.

\section{Synthesis of $d$ and $e$}

The mixture of c (640 mg, $4.6 \mathrm{mmol}), \mathrm{CS}_{2}(10 \mathrm{~mL}), \mathrm{AlCl}_{3}(3.1 \mathrm{~g}$, $13.8 \mathrm{mmol})$, and nitrobenzene $(8 \mathrm{~mL})$ was refluxed for $1 \mathrm{~h}$, and then n-butyryl chloride $(10 \mathrm{mmol})$ was added. The mixture was continuously stirred for $3 \mathrm{~h}$. The reaction was detected by TLC $($ EtOAc/petroleum $=1 / 1)$. The reaction solution was cooled to room temperature and was adjusted to $\mathrm{pH} 7$ with $\mathrm{HCl}$ and extracted with EtOAc. Solvent was evaporated to obtain the crude 


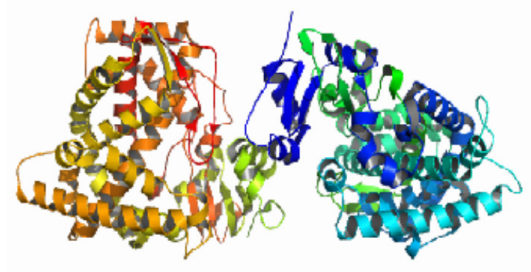

3LD6

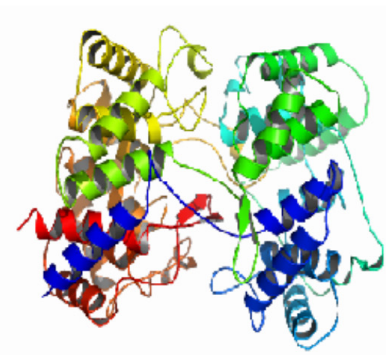

1SQC

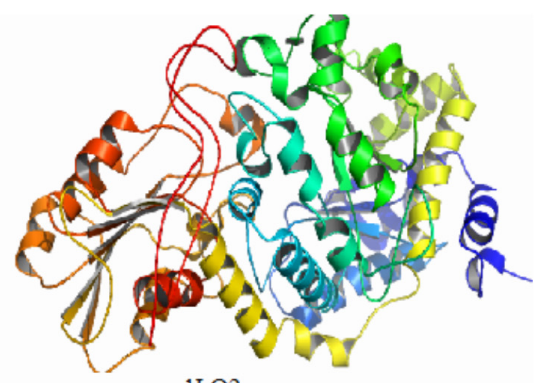

1LQ2

FIGURE 5 | Enzyme crystal complexes of 3LD6, 1SQC, 1LQ2.

TABLE 4 | -CDOCKER energy of compounds to three enzymes.

-CDOCKER energy

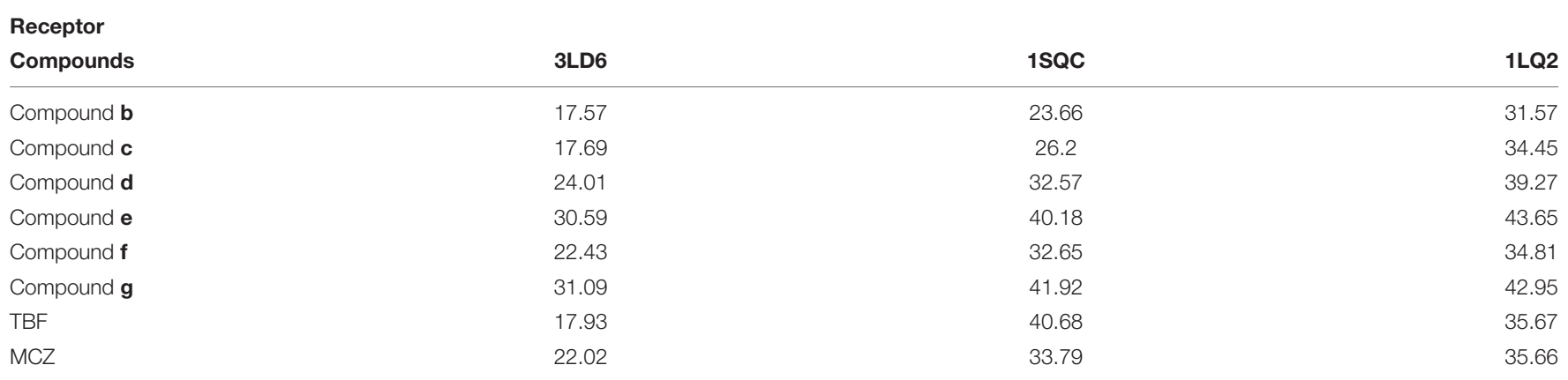

MCZ, miconazole nitrate; TBF, terbinafine hydrochloride.

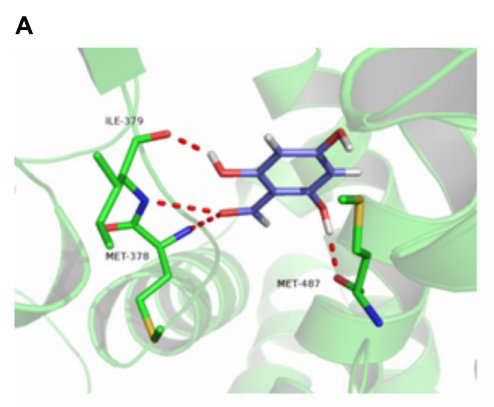

B

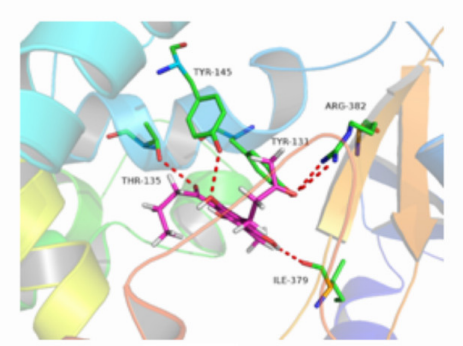

C

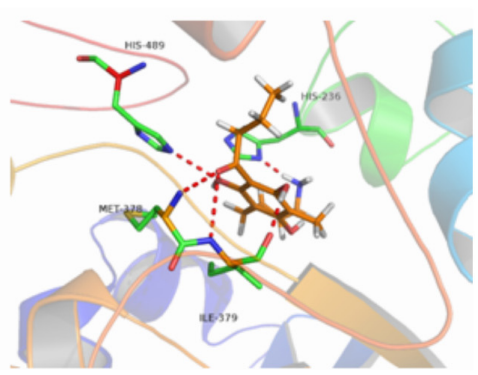

FIGURE 6 | 3D docking conformation of compounds with 3LD6: (A) 3D docking conformation of compound $\mathbf{b}$ with 3LD6; (B) 3D docking conformation of compound e with 3LD6; (C) 3D docking conformation of compound $\mathbf{g}$ with 3LD6.

product, which was purified by column chromatography with EtOAc/petroleum (1/3) to obtain $\mathrm{d}$ and $\mathrm{e}$.

\section{Synthesis of $f$}

The mixture of $\mathrm{c}(100 \mathrm{mg}, 9.2 \mathrm{mmol}), \mathrm{CH}_{2} \mathrm{Cl}_{2}(30 \mathrm{~mL})$, and $\mathrm{AlCl}_{3}$ (4.6 g, $18.4 \mathrm{mmol}$ ) was refluxed for $1 \mathrm{~h}$ and was added to a solution of 4-chloro-2-buten amine ( $975 \mathrm{mg}, 9.2 \mathrm{mmol}$ ) in $\mathrm{CH}_{2} \mathrm{Cl}_{2}$ and stirred for $12 \mathrm{~h}$ at room temperature and then treated with $10 \%$ hydrochloric acid. The organic layer was isolated and distilled under reduced pressure to remove $\mathrm{CH}_{2} \mathrm{Cl}_{2}$, and then was extracted with acetone. Solvent was evaporated to obtain the crude product, which was purified by column chromatography with EtOAc/petroleum (1/1) to obtain $\mathrm{f}$.

\section{Synthesis of $\mathrm{g}$}

Compound g was prepared in analogy to compound $\mathrm{d}$.

\section{In vitro Antifungal Assay Antifungal Agents}

A $16 \mathrm{mg} / \mathrm{mL}$ stock solution of compounds was prepared in dimethyl sulfoxide (DMSO) and stored at $-20^{\circ} \mathrm{C}$ in the dark (foiled wrapped). The antifungal agents fluconazole (FLC, 

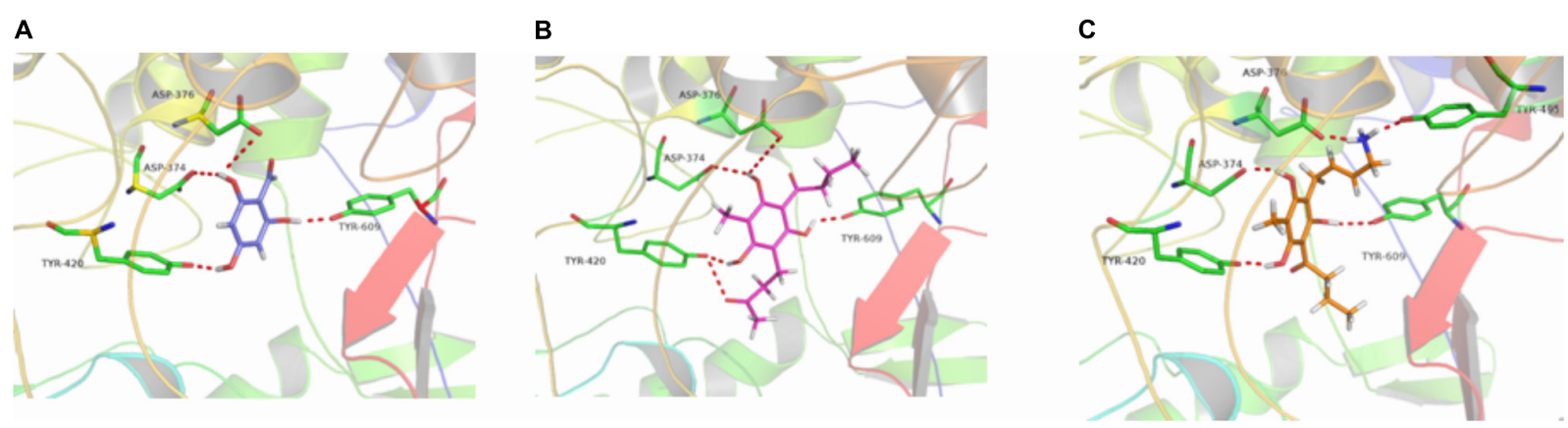

FIGURE 7 | 3D docking conformation of compounds with 1SQC: (A) 3D docking conformation of compound $\mathbf{b}$ with 1SQC; (B) 3D docking conformation of compound e with 1SQC; (C) 3D docking conformation of compound $\mathbf{g}$ with 1SQC.
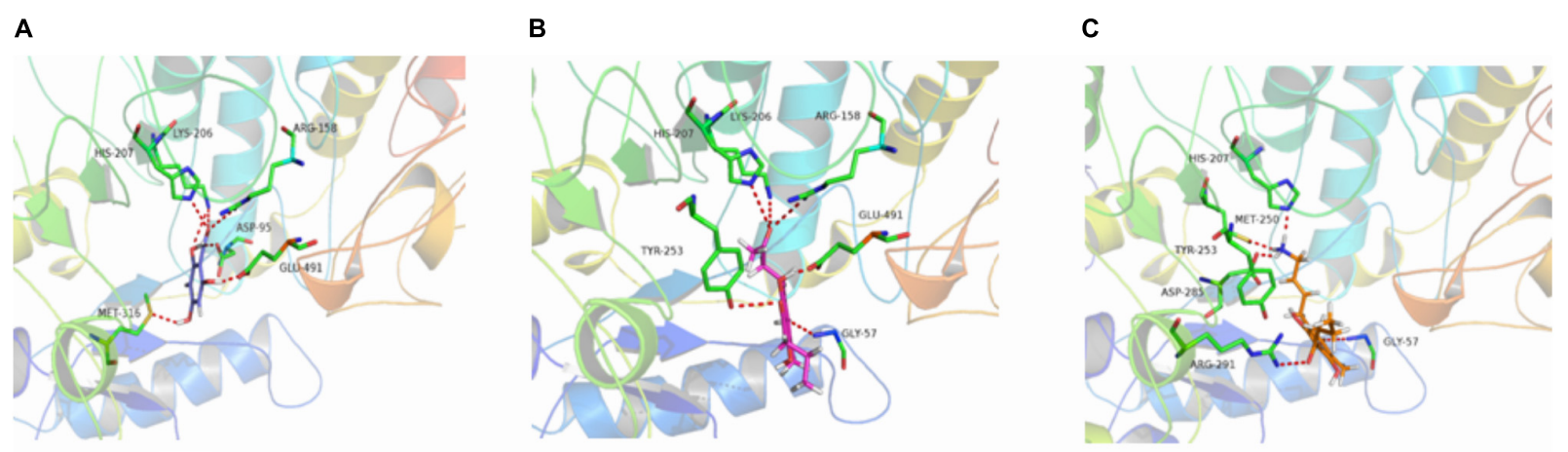

FIGURE 8 | 3D docking conformation of compounds with 1LQ2: (A) 3D docking conformation of compound $\mathbf{b}$ with 1LQ2; (B) 3D docking conformation of compound e with 1LQ2; (C) 3D docking conformation of compound $\mathbf{g}$ with 1LQ2.

A434403, 99\%) and TBF (M0T26A, >98\%) were obtained from Shouguang Fukang Pharmaceutical Inc. and Melone Pharmaceutical Inc. FLC and TBF were dissolved in normal saline at a final concentration of $2 \mathrm{mg} / \mathrm{mL}$ and were stored at $-20^{\circ} \mathrm{C}$. Compounds were mixed with potato dextrose agar (PDA).

\section{Organisms and Culture Conditions}

Trichophyton rubrum CMCC(F)T1a, T. mentagrophytes CMCC(F)T5a, G. M. bacteria MCC(F)M2C, and M. canis CMCC(F)Td were obtained from Institute of Dermatology, Chinese Academy of Medical Sciences (Nanjing). These dermatophytes were Candida parapsilosis. Filamentous fungi and dermatophytes were cultivated at $35^{\circ} \mathrm{C}$ in Roswell Park Memorial Institute (RPMI) 1640 medium (with L-glutamine, without sodium bicarbonate; Sigma-Aldrich, St. Louis, MO, United States) buffered to a $\mathrm{pH}$ of 7.0 with $0.165 \mathrm{M}$ morpholinepropanesulfonic acid buffer (Sigma-Aldrich).

\section{MIC Value Determination by the in vitro Antifungal Assay}

Disks of dermatophytes were obtained from cultures and were aseptically inoculated onto the center of each Petri plate with extract and control sets. The Petri plates were incubated at $35^{\circ} \mathrm{C}$ for 7 days. Fungal conidia were prepared by inoculating the fungal culture in normal saline $(0.01 \%$ Tween- 80$)$ and were adjusted to $1 \times 10^{4}-3 \times 10^{4} \mathrm{CFU} / \mathrm{mL}$. Then, they were distributed uniformly on PDA medium by sterilizing cotton swab. Sterile paper disks $(6.8 \mathrm{~mm})$ were impregnated with compounds and placed on the culture plates. The MICs and MFCs were determined by the broth micro dilution assay. MCZ and $\mathrm{TBF}$ as the positive control of this experiment were used after shaking; $100 \mathrm{~mL}$ of the solution was added to the wells of 96-well plates. Cell suspensions $(200 \mu \mathrm{L})$ containing 0.156$160 \mu \mathrm{g} / \mu \mathrm{L}$ of compounds were added to the wells of a 96-well microtiter plate and incubated for $48 \mathrm{~h}$ at $35^{\circ} \mathrm{C}$. The MIC was defined as the lowest concentration that completely inhibited visible fungal growth in the wells after 7 days of incubation. MFC was indicated by the well that showed no growth after culturing on PDA medium (CLSI, 2008).

\section{Time-Kill Curve Assays}

In order to understand the rate of the antidermatophyte activity, compounds e and $\mathbf{g}$ were selected for time-kill assays against $M$. canis owing to stronger inhibition of compounds $\mathbf{e}$ and $\mathbf{g}$ on $M$. canis. The efficacy of the compounds to eliminate $M$. canis was evaluated using a published protocol (Nishad et al., 2016). The time-kill curve took shape according to the plate colony counting method. Dermatophyte cells were incubated in PDA medium overnight; one part was taken out to achieve an $\mathrm{OD}_{600}$ of 0.20 , and the other part $(100 \mu \mathrm{L})$ was added to RPMI 1640 medium 

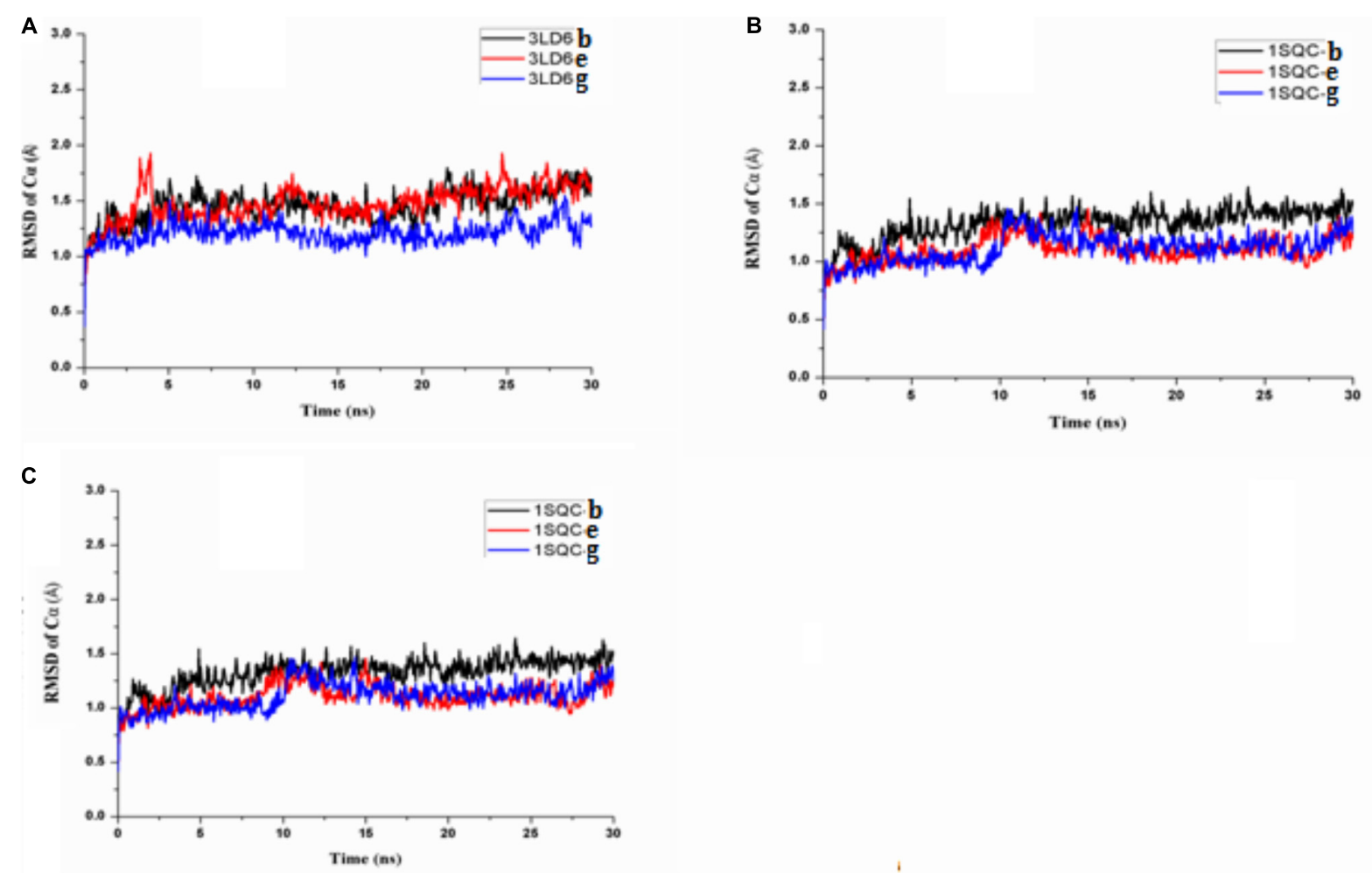

FIGURE 9 | Molecular dynamics simulation of compounds with 3LD6, 1SQC, and 1LQ2: (A) molecular dynamics simulation of compounds with 3LD6; (B) molecular dynamics simulation of compounds with 1SQC; (C) molecular dynamics simulation of compounds with 1LQ2.

in sterile culture tubes. MCZ, TBF, and compounds $\mathbf{e}$ and $\mathbf{g}$ were then added to the solution to achieve drug concentrations at 1/2MIC, MIC, and 2MIC and total volumes in each culture tube to $1.8 \mathrm{~mL}$. The tubes were then incubated at $35^{\circ} \mathrm{C}$ with continuous agitation (200 rpm) for $0,2,4,8,12,24,48,72$, and $96 \mathrm{~h}$. The second part was removed from each solution and serially diluted in sterile $\mathrm{ddH}_{2} \mathrm{O}$. Each dilution was then spread onto PDA plates and incubated at $35^{\circ} \mathrm{C}$. Colonies were then enumerated after $24-48 \mathrm{~h}$ of incubation. The experiments were performed in triple.

\section{Effect of Compounds e and $g$ on the Ergosterol Synthesis of $M$. canis}

Microsporum canis were cultured on PDA medium for a week at $32^{\circ} \mathrm{C}$ and $90 \%$ relative humidity and prepared to a concentration of $1.5 \times 10^{8} \mathrm{CFU} / \mathrm{mL}$ with sterile saline. To a $250 \mathrm{~mL}$ sterile flask, the $100 \mathrm{~mL}$ of RPMI 1640 medium was added to reach

TABLE 5 | The binding energy of compounds to three enzymes.

\begin{tabular}{lccc}
\hline & \multicolumn{3}{c}{ Binding energy } \\
\cline { 2 - 4 } & Compound $\mathbf{~}$ & Compound $\mathbf{~}$ & Compound b \\
\hline 1LQ2 & -6.67 & -7.04 & -5.95 \\
1SQC & -4.74 & -5.16 & -4.50 \\
3LD6 & -3.65 & -4.68 & -3.42
\end{tabular}

a concentration of $1 \times 10^{4} \mathrm{CFU} / \mathrm{mL}$ and cultured at $30^{\circ} \mathrm{C}$ for 3 days. The $5 \mathrm{~mL}$ fungal suspensions were added to a sterile centrifuge tube, followed by the addition of the drug as follows: control group, 1/2MIC compound e, MIC compound e, $2 \mathrm{MIC}$ compound e, $1 / 2 \mathrm{MIC}$ compound $\mathbf{g}$, MIC compound $\mathbf{g}$, 2MIC compound $\mathbf{g}$, 2MIC terbinafine, 2MIC miconazole, 2MIC caspofungin, cultured at $30^{\circ} \mathrm{C}$ for 3 days. Each was performed for three times. The supernatant was removed by centrifugation (3000 rpm, $3 \mathrm{~min}$ ); $10 \mathrm{~mL}$ of sterile distilled water was added, vortexed for $2 \mathrm{~min}$, and repeated three times. The $0.3 \mathrm{~g}$ of hyphae was added to $2 \mathrm{~mL}$ of the prepared $25 \% \mathrm{KOH}$ solution and heated for $1 \mathrm{~h}$ at $85^{\circ} \mathrm{C}$, cooled to room temperature, and extracted with petroleum ether $(10 \mathrm{~mL} \times 3)$. The organic layer was evaporated to dryness. Moderate $\mathrm{MeOH}$ was added to the residue and sonicated for $10 \mathrm{~min}$ and was set to $5 \mathrm{~mL}$. The ergosterol content in M. canis was investigated by UPLC (He et al., 2014).

\section{Effect of Compounds e and g on CYP51, SE, and $\beta-1,3-$ Glucan Synthase}

The effects of compounds e and $\mathbf{g}$ on CYP51, SE, and $\beta-1,3$ glucan synthase were investigated by ELISA using TBF, MCZ, and caspofungin acetate as positive control. The experiment was carried out according to a published protocol (Brian et al., 2012). Activities of compounds were measured in a polymerization assay in 96-well format. The experiment was divided into three 
groups: control group (pure enzyme), positive control group (pure enzyme plus positive drug), compound e groups (pure enzyme plus compound e) (1/2MIC, MIC, and 2MIC), and compound groups (pure enzyme plus compound $\mathbf{g}$ ) (1/2MIC, MIC, and 2MIC). There were three parallel wells in the blank control group and sample group and 2 parallel wells in the standard control group. The $50 \mu \mathrm{L}$ of distilled water was added to each well and incubated for $30 \mathrm{~min}$ at $37^{\circ} \mathrm{C}$. The reaction was stopped by the addition of $100 \mu \mathrm{L}$ of $20 \%$ trichloroacetic acid. Plates were chilled for a minimum of $10 \mathrm{~min}$, and washed with five cycles of water (about $1 \mathrm{~mL} /$ well each cycle) using a Packard Filtermate Harvester. Scintillation fluid (40 $\mu \mathrm{L} /$ well) (Packard ULTIMA GOLD TM-XR) was added and the sealed plates were counted in a WALLAC BETA counter in top-counting mode at an efficiency of approximately $40 \%$.

\section{Docking Studies Molecular Docking}

Molecular docking was performed with the CDOCKER program that was interfaced with Discovery Studio 2.5.5. The X-ray crystallographic structures of CYP51 (PDB ID: 3LD6), SE (PDB ID: 1SQC), and $\beta$-1,3-glucan synthase (PDB ID: 1LQ2) were taken from PDB (see text footnote 1) and were used as protein structures. Briefly, the ligands were docked into the corresponding protein's binding site complied with the protocol, which was generated by ligands from the crystal structures of 3LD6, 1SQC, and 1LQ2 with random hydrogen atoms and GasteigereHückel charges but not water, and other parameters were default values except that the threshold was 1. The structures of receptors were minimized to 10,000 cycles using the Powell method in DS 2.5.5. The geometries of all compounds were optimized by the conjugate gradient method of TRIPOS. The convergence criterion was identified as $0.001 \mathrm{kcal} / \mathrm{mol}$.

\section{Simulations}

The molecular dynamics simulations were performed on the basis of molecular docking using AMBER 9.0 for ligands and AMBER ff03 for protein, using Gaussian 09 soft to calculate electrostatic potential, and using Antechamber/RESP/ESP to obtain atomic charge. The program selected TIP3P water model and added $\mathrm{Na}^{+}$to maintain electrical neutrality. The heating operation was carried out from 0 to $300 \mathrm{~K}$ in 100 ps using Langevin dynamics at a constant volume, which included 2500 cycles of steepest descent minimization, followed by 2500 cycles of conjugated gradient minimization. Finally, periodic boundary conditions of $30 \mathrm{~ns}$ were performed for the whole system with a normal pressure of $1 \mathrm{~atm}$ and a normal temperature of $300 \mathrm{~K}$ in the production step.

\section{CONCLUSION}

Six methylphloroglucinol derivatives were successfully synthesized. The phenolic hydroxyl group of the phloroglucinols was the active group of compounds. 2,6-Dibutyryl-4methylbenzene-1,3,5-triol (e) and (E)-6-(4-aminobut-2-enyl)2-butyryl-4-methylbenzene-1,3,5-triol (g) showed stronger antidermatophyte activities than other compounds. The antidermatophyte mechanism was that compounds made the ergosterol content in $M$. canis decrease by inhibiting the activities of CYP51 and SE, which resulted in synthesis failure of the cell film, blocking the synthesis of the fungal cell wall by inhibiting $\beta$-1,3-glucan synthase. The docking experiment showed that compounds $\mathbf{e}$ and $\mathbf{g}$ had higher binding energies in accordance with the results of antidermatophyte activities, which further confirmed inhibition of compounds e and $\mathbf{g}$ on CYP51, SE, and $\beta$-1,3-glucan synthase. This study can supply some antidermatophyte leading structure and possible mechanism for studying and developing new antifungal agents, and it can give foundation of the development of new antifungal drugs of independent intellectual property rights.

\section{AUTHOR CONTRIBUTIONS}

ZS and LY contributed to the conception and design of the experiments, analysis of the data, and revision of the paper. PL selected and analyzed the data. YW and CT performed the biological studies. WD performed the docking studies.

\section{FUNDING}

This work was supported by the Special Innovation Project of Guangdong Education Department (Natural Science) (2017KTSCX107), Guangdong Natural Science Foundation (2015A03031356), Science and Technology Planning Project of Guangdong Province (2017ZC0199), Guangdong Provincial Applied Scientific and Technological Project (2015B020234009), National Scientific and Technological Project of Traditional Chinese Medicine Industry (201507004), Guangdong Pharmaceutical University "School Powered by Innovation" Foundation of China (2016KZDXM039), and Guangdong special training fund for university students' scientific and technological innovation (51328004).

\section{ACKNOWLEDGMENTS}

The authors are grateful to Mr. Tan and Sun Yat-sen University for the molecular docking experiment.

\section{SUPPLEMENTARY MATERIAL}

The Supplementary Material for this article can be found online at: https://www.frontiersin.org/articles/10.3389/fmicb. 2018.02262/full\#supplementary-material 


\section{REFERENCES}

Araj, G. F., Asmar, R. G., and Avedissian, A. Z. (2015). Candida profiles and antifungal resistance evolution over a decade in Lebanon. J. Infect. Dev. Ctries. 9, 997-1003. doi: 10.3855/jidc.6550

Brian, H. H., Gregory, J. P., Ahmed, M., Hao, L., Kingsley, N., Ghjuvanni, C., et al. (2012). Synthesis and biological evaluation of antifungal derivatives of enfumafungin as orally bioavailable inhibitors of $\beta$-1,3-glucan synthase. Bioorg. Med. Chem. Lett. 22, 6811-6816. doi: 10.1016/j.bmcl.2012.05.031

CLSI (2008). Reference Method for Broth Dilution Antifungal Susceptibility Testing of Filamentous Fungi; Approved Standard CLSI Document M38-A2. Wayne: Clinical and Laboratory Standards Institute.

Du, W. Z., Song, G. Q., Liu, H. Y., Feng, D. K., and Shen, Z. B. (2016). Study on phloroglucinol derivatives of Dryopteris fragrans (L.)Schott. J. Guangdong Pharm. Univ. 32, 22-24.

Gao, C., Guo, N., Li, N., Peng, X., Wang, P., Wang, W., et al. (2016). Investigation of antibacterial activity of aspidin BB against Propionibacterium acnes. Arch. Dermatol. Res. 308, 79-86. doi: 10.1007/s00403-015-1603-x

Gil-Alonso, S., Jauregizar, N., Eraso, E., and Quindós, G. (2016). Postantifungal effect of caspofungin against the Candida albicans and Candida parapsilosis clades. Diagn. Microbiol. Infect. Dis. 86, 172-177. doi: 10.1016/j.diagmicrobio. 2016.07.011

He, W. S., Yin, J., Xu, H. S., Qian, Q. Y., Jia, C. S., Ma, H. L., et al. (2014). Efficient synthesis and characterization of ergosterol laurate in a solvent-free system. J. Agric. Food Chem. 62, 11748-11755. doi: 10.1021/jf504516q

Huang, K. X., Xia, L., Zhang, Y., Ding, X., and Zahn, J. A. (2009). Recent advances in the biochemistry of spinosyns. Appl. Microbiol. Biotechnol. 82, 13-23. doi: 10.1007/s00253-008-1784-8

Huang, Y. X., Shen, Z. B., Jiang, T., Chen, Y. F., Liu, J. Y., Zhang, L., et al. (2016). Antifungal effect of the active fraction of Dryopteris fragrans on Trichophyton rubrum in vitro. J. Guangdong Pharm. Univ. 32, 78-82.

Kathiravan, M. K., Salake, A. B., Chothe, A. S., Dudhe, P. B., Watode, R. P., Mukta, M. S., et al. (2012). The biology and chemistry of antifungal agents: a review. Bioorg. Med. Chem. 20, 5678-5698. doi: 10.1016/j.bmc.2012.04.045

Li, N., Gao, C., Peng, X., Wang, W., Luo, M., Fu, Y. J., et al. (2014). Aspidin BB,a phloroglucinol derivative,exerts its antibacterial activity against Staphylococcus aureus by inducing the generation of reactive oxygen species. Res. Microbiol. 165, 263-272. doi: 10.1016/j.resmic.2014.03.002

Lin, P. F., Yang, S. H., Qi, Y., Ye, L. B., Tang, C. P., and Shen, Z. B. (2018). Synthesis and in vitro antifungal effects of pseudoaspidinol and derivatives. Chin. J. Med. Chem. 28, 15-19.

Mazu, T. K., Bricker, B. A., Flores-Rozas, H., and Ablordeppey, S. Y. (2016). The mechanistic targets of anti-fungal agents: an overview. Mini Rev. Med. Chem. 16, 555-578. doi: 10.2174/1389557516666160118112103
Nishad, T. C., Sanjib, K. S., Huy, X. N., and Sylvie, G. T. (2016). Synthesis and investigation of novel benzimidazole derivatives as antifungal agents. Bioorg. Med. Chem. 24, 3680-3686. doi: 10.1016/j.bmc.2016.06.010

Ruhnke, M., Rickerts, V., and Cornely, O. A. (2011). Diagnosis and therapy of Candida infections: Joint recommendations of the German Speaking Mycological Society and the Paul-Ehrlich-Society for Chemotherapy. Mycoses 54, 279-310. doi: 10.1111/j.1439-0507.2011.02040.x

Shrestha, S. K., Garzan, A., and Garneautsodikova, S. (2017). Novel alkylated azoles as potent antifungals. Eur. J. Med. Chem. 133, 309-318. doi: 10.1016/j.ejmech. 2017.03.075

Sun, Y., Mu, F., Li, C., Wang, W., Luo, M., Fu, Y., et al. (2013). Aspidin BB, a phloroglucinol derivative, induces cell cycle arrest and apoptosis in human ovarian HO-8910 cells. Chem. Biol. Interact. 204, 88-97. doi: 10.1016/j.cbi.2013. 04.008

Tsui, C., Kong, E. F., and Jabrarizk, M. A. (2016). Pathogenesis of Candida albicans biofilm. Pathog. Dis. 74:ftw018.

Wan, J. F., Shen, Z. B., Jiang, T., Tang, C. P., and Wang, J. (2014). In Vitro antifungal activity of active fraction of dryopteris fragrans against sporothrix schenckii complex in yeast phase. Tradit. Chin. Drug Res. Clin. Pharmacol. 25, 44-48.

Wang, J., Tang, C. P., Jiang, T., Shen, Z. B., Chen, Y. F., and Huang, Y. X. (2015). Antifungal effect of the active fraction of Dryopteris fragrans on Malassezia furfur in vitro. Chin. Tradit. Pat. Med. 37, 642-645.

Xie, H. W., Yang, X. S., and Chao-Tian, L. (2015). Antifungal drugs and their mechanisms of action. Chin. J. Microecol. 27, 1477-1479.

Yang, S. H. (2017). Study on Manufacture and Antifungal of Pseudoaspidinol B and Aspidinol B[D]. Guangzhou: Guangdong Pharmaceutical University.

Yang, X. X., and Xu, Y. (2016). Cytochrome P450 monooxygenases and interaction of CYP125A18 with Azole Drugs in Rhodococcus sp.R04. Chin. J. Biochem. Mol. Biol. 3, 295-304.

Zhao, D. D., Zhao, Q. S., Liu, L., Chen, Z. Q., Zeng, W. M., Lei, H., et al. (2014). Compounds from Dryopteris fragrans( L ) schott with cytotoxic activity. Molecules 19, 3345-3355. doi: 10.3390/molecules19033345

Conflict of Interest Statement: The authors declare that the research was conducted in the absence of any commercial or financial relationships that could be construed as a potential conflict of interest.

Copyright (C) 2018 Ye, Lin, Du, Wang, Tang and Shen. This is an open-access article distributed under the terms of the Creative Commons Attribution License (CC BY). The use, distribution or reproduction in other forums is permitted, provided the original author(s) and the copyright owner(s) are credited and that the original publication in this journal is cited, in accordance with accepted academic practice. No use, distribution or reproduction is permitted which does not comply with these terms. 